\title{
CORRECTION
}

Check for updates

Cite this: J. Mater. Chem. A, 2018, 6, 23906

DOI: $10.1039 / c 8 t a 90268 b$

www.rsc.org/MaterialsA

\section{Correction: Boosting the oxygen reduction activity of a three-dimensional network Co-N-C electrocatalyst via space-confined control of nitrogen-doping efficiency and the molecular-level coordination effect}

\author{
Chaozhong Guo, ${ }^{\text {a }}$ Yanrong Li, ${ }^{\mathrm{b}}$ Wenli Liao, ${ }^{\mathrm{a}}$ Yao Liu, ${ }^{a}$ Zhongbin $\mathrm{Li}^{,}{ }^{\mathrm{a}}$ Lingtao Sun, ${ }^{\mathrm{a}}$ \\ Changguo Chen, ${ }^{c}$ Jin Zhang, ${ }^{\text {ab }}$ Yujun $\mathrm{Si}^{\star d}$ and $\mathrm{Lu} \mathrm{Li}^{\star \mathrm{a}}$ \\ Correction for 'Boosting the oxygen reduction activity of a three-dimensional network Co-N-C \\ electrocatalyst via space-confined control of nitrogen-doping efficiency and the molecular-level \\ coordination effect' by Chaozhong Guo et al., J. Mater. Chem. A, 2018, 6, 13050-13061.
}

The authors would like to correct an error in the published Acknowledgements. The Acknowledgements section should read as shown below:

This study was financially supported by the National Natural Science Foundation of China (Project No. 21805024), the Open Project of Engineering Research Center of New Energy Storage Devices and Applications of Chongqing Municipality (KF20170201), the Scientific and Technological Research Program of Chongqing Municipal Education Commission (KJ1711289), the Basic and Frontier Research Program of Chongqing Municipality (cstc2018jcyjAX0461), the Scientific Research Program of Chongqing University of Arts and Sciences (P2016XC07, M2017ME15) and the Innovation Team Project of Chongqing Municipal Education Commission (CXTDX201601037). We gratefully thank Dr Qin Xiang, Liangliang Tian, Jiahong He and Wenjing Yang for helpful discussions.

The Royal Society of Chemistry apologises for these errors and any consequent inconvenience to authors and readers.

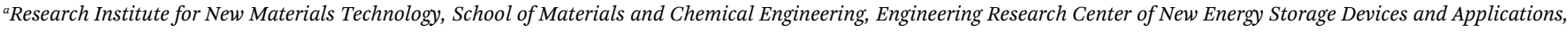
Chongqing University of Arts and Sciences, Chongqing 402160, China. E-mail: guochaozhong1987@163.com; lilu25977220@163.com

${ }^{b}$ College of Materials Science and Engineering, College of Chemistry and Chemical Engineering, Chongqing University of Technology, Chongqing 400054, China

${ }^{c}$ College of Chemistry and Chemical Engineering, Chongqing University, Shapingba, Chongqing 400044, China

${ }^{d}$ College of Chemistry and Environmental Engineering, Sichuan University of Science and Engineering, Zigong, 643000, China. E-mail: syj08448@163.com
} 